\title{
Effects of IRF1 and IFN- $\beta$ interaction on the M1 polarization of macrophages and its antitumor function
}

\author{
CHANGLI XIE, CUIYING LIU, BITAO WU, YAN LIN, TINGTING MA, \\ HAIYU XIONG, QIN WANG, ZIWEI LI, CHENYU MA and ZHIGUANG TU
}

\begin{abstract}
Key Laboratory of Diagnostic Medicine Designated by the Chinese Ministry of Education, Chongqing Medical University, Chongqing 400016, P.R. China
\end{abstract}

Received November 6, 2015; Accepted April 18, 2016

DOI: $10.3892 /$ ijmm.2016.2583

\begin{abstract}
Macrophages that differentiate from precursor monocytes can be polarized into a classically activated (M1) or alternatively activated (M2) status depending on different stimuli. Generally, interferon (IFN)- $\gamma$ and lipopolysaccharide (LPS) are considered the classical stimuli with which to establish M1 polarization. IFN regulatory factor (IRF)1 and IFN- $\beta$ are two crucial molecules involved in IFN- $\gamma$ - and LPS-initialed signaling. However, the association between IRF1 and IFN- $\beta$ in the context of the M1 polarization of macrophages is not yet fully understood. In this study, we demonstrate that U937-derived macrophages, in response to IFN- $\gamma$ and LPS stimulation, readily acquire an M1 status, indicated by the increased expression of interleukin (IL)-12, IL-6, IL-23, tumor necrosis factor (TNF)- $\alpha$ and the M1-specific cell surface antigen, CD86, and the decreased expression of the M2-specific mannose receptor, CD206. However, the knockdown of IRF1 in U937-derived macrophages led to an impaired M1 status, as indicated by the decreased expression of the above-mentioned M1 markers, and the increased expression of the M2 markers, CD206 and IL-10. A similar phenomenon was observed in the M1 macrophages in which IFN- $\beta$ was inhibited. Furthermore, we demonstrated that IRF1 and IFN- $\beta$ may interact with each other in the IFN- $\gamma$ - and LPS-initiated signaling pathway, and contribute to the IRF5 regulation of M1 macrophages. In addition, the conditioned medium collected from the M1 macrophages in which IRF1 or IFN- $\beta$ were inhibited, exerted pro-tumor effects on the HepG2 and SMMC-7721 cells, as indicated by an increase in proliferation, the inhibition of apoptosis and an enhanced invasion capability. The findings of our study suggest that the interactions of IRF1, IFN- $\beta$ and IRF5 are involved in the M1 polarization of macro-
\end{abstract}

Correspondence to: Dr Zhiguang Tu, Key Laboratory of Diagnostic Medicine Designated by the Chinese Ministry of Education, Chongqing Medical University, 1 Yixueyuan Road, Yuzhong, Chongqing 400016, P.R. China

E-mail: tuzhiguang@aliyun.com

Key words: interferon regulatory factor 1 , interferon- $\beta$, interferon regulatory factor 5, M1 polarization, antitumor phages and have antitumor functions. These data may provide a novel antitumor strategy for targeted cancer therapy.

\section{Introduction}

Macrophages are a heterogeneous and plastic cell population, which play crucial roles in the innate and adaptive immune response. They can undergo a phenotypically dynamic switch in response to different microenvironments (1). In general, two major macrophage subsets, including classically activated (M1) and alternatively activated (M2) macrophages, have long been recognized (2-4). M1 macrophages are classically induced by $\mathrm{T}$ helper type 1 (Th1) cytokines, such as interferon (IFN)- $\gamma$, and bacterial lipopolysaccharide (LPS). They express high levels of CD86, as well as a profile of pro-inflammatory cytokines, such as interleukin (IL)-12, IL-23, IL-6 and tumor necrosis factor (TNF)- $\alpha$, but low levels of CD206, and the anti-inflammatory cytokines, IL-10 and transforming growth factor (TGF)- $\beta$. By contrast, M2 macrophages are induced by T helper type 2 (Th2) cytokines, such as IL-4. They are characterized by a high expression of CD206, IL-10 and TGF- $\beta$, and a low expression of CD86 and a set of pro-inflammatory cytokines (5-10).

Macrophages play different roles in diseases, depending on their distinct phenotypes $(2,11,12)$. In tumor immunity, there is accumulating evidence to indicate that M1 macrophages are tumoricidal. It has been demonstrated that M1 macrophages are the dominant subset in colon carcinomas, which was related to diminished metastasis and increased survival rate (14). However, M2 macrophages facilitate tumor progression by promoting migration, angiogenesis and invasion (13). It has been reported that a high $\mathrm{M} 1 / \mathrm{M} 2$ ratio is associated with an improved survival in solid tumors, and the presence of M2 macrophages is considered responsible for a poor prognosis and enhanced disease progression in breast cancer $(14,15)$. Collectively, macrophage polarization may have promising applications in the field of tumor immune therapy.

It has been well established that IFN- $\gamma$ and LPS are two key stimuli which induce the M1 polarization of macrophages $(2,16)$. Although IFN- $\gamma$ and LPS play significant roles in the activation of M1 macrophages, they mediate distinct pathways. IFN- $\gamma$ exerts its biological effects primarily by activating the Janus kinase 1 (JAK1)/signal transducer and activator of transcription (STAT)1 signaling pathway (17). 
Interferon regulatory factor (IRF)1, a transcriptional regulator, is only weakly expressed in resting macrophages, but can be strongly upregulated by IFN- $\gamma$ stimulation $(18,19)$. In macrophages, IRF1 takes part in the regulation of IL-12 and inducible nitric oxide synthase (iNOS) $(20,21)$. On the other hand, LPS is recognized by Toll-like receptor 4 (TRL4) and activates MyD88-dependent or TRIF-dependent pathways (22). IFN- $\beta$ is one of the significant molecules involved in the TRIF-dependent pathway (23). It has also been demonstrated that IFN- $\beta$ plays a role in the regulation of IL-12p70 production in granulocytemacrophage colony-stimulating factor (GM-CSF)-induced bone marrow-derived macrophages (GM-BMM) (24); however, the mechanisms involved remain unclear. It should be noted that IRF1 was originally discovered as a transcriptional activator of IFN- $\beta$ in virus infected fibroblasts (25). Moreover, IRF1 can bind to the IFN-stimulated responsive element (ISRE)/ IRF-E site induced by IFN- $\beta$ (26). Furthermore, it has been clearly demonstrated that IRF1 nuclear expression in human monocytes is principally induced by a combination of IFN- $\gamma$ and LPS, rather than by either stimuli alone, which differs from that in mouse peritoneal macrophages or RAW 264.7 cells (27). Therefore, we could envisage the possible synergistic action of IRF1 and IFN- $\beta$, which are involved in the two independent, but complementary pathways induced by IFN- $\gamma$ and LPS in the M1 polarization of macrophages.

In addition, several recent studies have identified a dual function of IRF5 in activating M1 genes (IL-12p35, IL-12p40, IL-23p19, IL-6 and TNF- $\alpha$ ), while suppressing M2 genes (IL-10 and TGF- $\beta$ ) (28-30). Human IRF5 presents multiple alternatively spliced isoforms (V1-V9), which are cell type-specific. It has been shown that V1 and V3 possess different transcription start sites and are modulated by two distinct promoters. The $\mathrm{V} 1$ promoter (P-V1) contains the IRF-E consensus binding site, and the V3 promoter (P-V3) contains an ISRE-binding site (31). Interestingly, both IRF-E and ISRE can be recognized by IRF1 (32) or by the transcripts complex induced by IFN- $\beta(33,34)$. However, the involvement of the interaction of IRF1, IFN- $\beta$ and IRF5 in the M1 polarization of macrophages not yet fully understood.

Based on above-mentioned data, we could reasonably hypothesize that there may exist a certain association between IRF1, IFN- $\beta$ and IRF5, and the M1 polarization of macrophages, or that the three may interact with each other to promote the M1 polarization of macrophages. Therefore, in this study, we examined the interactions of IRF1 and IFN- $\beta$, particularly the regulation of IRF5, and their role in the M1 polarization of macrophages and M1 macrophage-mediated antitumor effects on hepatocellular carcinoma (HCC) cell lines.

\section{Materials and methods}

Cell culture. The monocyte cell line, U937, was obtained from the American Type Culture Collection (ATCC; Manassas, VA, USA). The cells were maintained in RPMI-1640 medium (HyClone, Logan, UT, USA), supplemented with $10 \%$ fetal bovine serum (FBS; Biological Industries, Kibbutz Beit-Haemek, Israel) and $1 \%$ penicillin and streptomycin. According to previous studies $(10,35,36)$, U937 monocytes were differentiated into unpolarized macrophages (M0) by $5 \mathrm{ng} / \mathrm{ml}$ phorbol 12-myristate 13-acetate (PMA) (S1819;
Beyotime Biotechnology, Jiangsu, China) for $48 \mathrm{~h}$. To establish the M1 polarization of macrophages, the M0 macrophages were stimulated with $20 \mathrm{ng} / \mathrm{ml}$ IFN- $\gamma$ (no. 300-02; Peprotech, Rocky Hill, NJ, USA) and 100 ng/ml LPS (no. LZ880; SigmaAldrich, St. Louis, MO, USA) for an additional $24 \mathrm{~h}$.

SMMC-7721 HCC cells were obtained from the Shanghai Institutes for Biological Sciences (Shanghai, China). HepG2 HCC cells were obtained from ATCC. The cells were both maintained in DMEM (HyClone), supplemented with 10\% FBS (Biological Industries) and 1\% penicillin and streptomycin.

Analysis of macrophage surface marker expression. Phenotypic analysis of the macrophages was performed using flow cytometry. In brief, the cells were collected and washed 3 times with ice-cold PBS. Firstly, the cells were incubated with ice-cold PBS containing 5\% mice serum at $4{ }^{\circ} \mathrm{C}$ to avoid non-specific binding. The cells were then stained for anti-humanCD86-PE (no. 305405) or anti-human-CD206-PE (no. 321105) antibodies (both from BioLegend, San Diego, CA, USA) for $30 \mathrm{~min}$. After immunostaining, the cells were washed twice with PBS and analyzed using the BD Influx ${ }^{\mathrm{TM}}$ cell sorter flow cytometer (BD Biosciences, San Jose, CA, USA). Isotype control cells used for non-specific background staining were stained with PE-labeled mouse IgG1K iso control PE (E114181634; eBioscience, Inc., San Diego, CA, USA).

Enzyme-linked immunosorbent assay (ELISA). After the U937-M0 cells were stimulated with IFN- $\gamma(20 \mathrm{ng} / \mathrm{ml})$ and LPS $(100 \mathrm{ng} / \mathrm{ml})$ for $24 \mathrm{~h}$, the supernatant was collected and centrifuged at $1,800 \mathrm{x} \mathrm{g}$ at $4^{\circ} \mathrm{C}$ for $10 \mathrm{~min}$. The IL-12p70 and IL-10 secretion levels were measured using ELISA MAX ${ }^{\mathrm{TM}}$ Deluxe Sets (nos. 431706 and 430607; BioLegend). The IFN- $\beta$ levels were measured using an ELISA kit for human IFN- $\beta$ (SEA222Hu; Cloud-Clone Corp., Houston, TX, USA) in accordance with the manufacturer's instructions. Each experiment was repeated 3 times. The final outcomes were pooled as the average concentration of cytokines.

Western blot analysis. According to the above-mentioned cell culture, the M1 macrophages were collected and total protein was extracted using radio immunoprecipitation assay (RIPA) lysis buffer (Roche Diagnostics, Basel, Switzerland) and phenylmethanesulfonyl fluoride (PMSF; Beyotime Biotechnology) at 100:1. The protein concentration was quantified by BCA assay. The supernatant containing $40 \mu \mathrm{g}$ total protein was extracted for electrophoresis on a $12 \%$ sodium dodecyl sulfate gel (SDS; Beyotime) and then transferred onto $0.45 \mathrm{~nm}$ polyvinylidene fluoride membranes (PVDF; Millipore, Billerica, MA, USA). After being blocked with 5\% non-fat powdered milk in Tris-buffered saline containing $0.1 \%$ Tween-20 (TBST) for $1.5 \mathrm{~h}$, the membranes were incubated at $4^{\circ} \mathrm{C}$ overnight with moloclonal rabbit anti-IRF1 (D5E4) or anti-IRF5 (E1N9G) antibodies (1:1,000; Cell Signaling Technology, Danvers, MA, USA) or rabbit anti- $\beta$-actin antibody (1:1,000, YT0099; ImmunoWay Biotechnology, Co., Newark, DE, USA) as the primary antibodies. This was followed by incubation with horseradish peroxidase-conjugated AffiniPure goat anti-rabbit secondary antibody (1:2,000, ZB-2301; ZSGB-BIO, Beijing, China) at room temperature for $2 \mathrm{~h}$. The immunoreactive complexes were visualized by enhanced chemiluminescence (ECL) (Millipore). The 
Table I. Sequences of oligonucleotide primers used for RT-qPCR.

\begin{tabular}{|c|c|c|c|}
\hline Gene & Sequence & Orientation & Amplification size (bp) \\
\hline$\beta$-actin (NM_001101.3) & $\begin{array}{l}\text { CTGGGACGACATGGAGAAAA } \\
\text { AAGGAAGGCTGGAAGAGTGC }\end{array}$ & $\begin{array}{l}\text { Sense } \\
\text { Antisense }\end{array}$ & 564 \\
\hline p40 (NM_002187.2) & $\begin{array}{l}\text { CTCTGGCAAAACCCTGACC } \\
\text { GCTTAGAACCTCGCCTCCTT }\end{array}$ & $\begin{array}{l}\text { Sense } \\
\text { Antisense }\end{array}$ & 85 \\
\hline p35 (NM_000882.3) & $\begin{array}{l}\text { ACCAGGTGGAGTTCAAGACC } \\
\text { TGGCACAGTCTCACTGTTGA }\end{array}$ & $\begin{array}{l}\text { Sense } \\
\text { Antisense }\end{array}$ & 134 \\
\hline IL-10 (NM_000572.2) & $\begin{array}{l}\text { GATGCCTTCAGCAGAGTGAA } \\
\text { ACCCTTAAAGTCCTCCAGCA }\end{array}$ & $\begin{array}{l}\text { Sense } \\
\text { Antisense }\end{array}$ & 93 \\
\hline IFNBI (NM_002176.2) & $\begin{array}{l}\text { AGGACAGGATGAACTTTGAC } \\
\text { TGATAGACATTAGCCAGGAGGTT }\end{array}$ & $\begin{array}{l}\text { Sense } \\
\text { Antisense }\end{array}$ & 183 \\
\hline IRF5 (NM_001098627.2) & $\begin{array}{l}\text { AGGGCTTCAATGGGTCAAC } \\
\text { ACGCCTTCGGTGTATTTCC }\end{array}$ & $\begin{array}{l}\text { Sense } \\
\text { Antisense }\end{array}$ & 141 \\
\hline IRF1 (NM_002198.2) & $\begin{array}{l}\text { GCTGGGACATCAACAAGGAT } \\
\text { CCTGCTCTGGTCTTTCACCT }\end{array}$ & $\begin{array}{l}\text { Sense } \\
\text { Antisense }\end{array}$ & 164 \\
\hline IL-6 (NM_000600.3) & $\begin{array}{l}\text { ATGTGTGAAAGCAGCAAAGAG } \\
\text { CACCAGGCAAGTCTCCTCA }\end{array}$ & $\begin{array}{l}\text { Sense } \\
\text { Antisense }\end{array}$ & 111 \\
\hline IL-23p19 (NM_016584) & $\begin{array}{l}\text { AATCCTTCGCAGCCTCCA } \\
\text { TGAGTGCCATCCTTGAGC }\end{array}$ & $\begin{array}{l}\text { Sense } \\
\text { Antisense }\end{array}$ & 105 \\
\hline TNF- $\alpha$ (NM_000594) & $\begin{array}{l}\text { CGAGTGACAAGCCTGTAGCC } \\
\text { TTGAAGAGGACCTGGGAGTAG }\end{array}$ & $\begin{array}{l}\text { Sense } \\
\text { Antisense }\end{array}$ & 172 \\
\hline
\end{tabular}

IL, interleukin; IFN, interferon; IRF, interferon regulatory factor; TNF, tumor necrosis factor.

intensities of the protein bands were quantified using Bio-Rad Quantity One software (Bio-Rad Laboratories, Inc., Hercules, CA, USA). $\beta$-actin antibody was used to normalize the results.

Total RNA isolation and reverse transcription-quantitative $P C R(R T-q P C R)$. The U937 cells were stimulated with PMA or IFN- $\gamma+$ LPS for 2, 4, 6, 8, 12 and $24 \mathrm{~h}$. Total RNA was isolated from the macrophages using TRIzol reagent (Takara Bio, Inc., Otsu, Japan) and a total of $1 \mu \mathrm{g}$ of RNA was subjected to reverse transcription reactions using the PrimeScript ${ }^{\mathrm{TM}} \mathrm{RT}$ reagent kit (no. RR047A; Takara Bio, Inc.) in accordance with the manufacturer's instructions. qPCR was conducted with SYBR Premix Ex Taq ${ }^{\mathrm{TM}}$ II (no. RR820A; Takara Bio, Inc.) on the Bio-Rad CFX-Connext Real-Time PCR Detection system (BioRad, Philadelphia, PA, USA) with the following steps: $95^{\circ} \mathrm{C}$ for $10 \mathrm{sec}, 59^{\circ} \mathrm{C}$ for $30 \mathrm{sec}$, and $72^{\circ} \mathrm{C}$ for $30 \mathrm{sec}$ for $39 \mathrm{cycles}$. The primers specific for our target genes are listed in Table I. $\beta$-actin was used as an internal control for normalization. The data were analyzed using the $2^{-\Delta \Delta \mathrm{Ct}}$ method. Each experiment was repeated 3 times. All RT-qPCR reactions were performed in triplicate.

Neutralization of IFN- $\beta$. To determine the effects of IFN- $\beta$ on the polarization of macrophages, anti-IFN- $\beta$ antibody (no Ab6979; Abcam Inc., Cambridge, MA, USA) was utilized to neutralize IFN- $\beta$ secreted in the supernatant according to the manufacturer's instructions. Briefly, the anti-IFN- $\beta$ antibody was added to the medium after the U937 cells were treated with PMA. Three hours later, the cells were stimu- lated with IFN- $\gamma$ and LPS for different periods of time for the next experiment.

Small interfering RNA (siRNA)-mediated gene knockdown. The unpolarized macrophages (M0) were treated with siRNA specific to IRF1 or IFNB1 (RioboBio Co., Guangzhou, China). Non-targeting siRNA served as the control (siC). Three siRNA sequences were designed for the siRNAs specific to IRF1 or IFNB1 . The one that had the highest silencing efficiency was used in the following experiments. siRNA transfection was performed using the RNAiMAX reagent (no. 13778100; Invitrogen Trading Co., Ltd, Shanghai, China) according to the manufacturer's instructions. Briefly, RNAiMAX reagent and siRNA were diluted with Optimedium, respectively, and then mixed gently in an equal volume at room temperature for $20 \mathrm{~min}$. Subsequently, $500 \mu \mathrm{l}$ mixture and $1.5 \mathrm{ml}$ complete RPMI-1640 medium without penicillin and streptomycin were added to each well of a 6-well plate. The cells were counted under a microscope before they were added to the 6 -well plate and approximately $1 \times 10^{6}$ cells were added to each well. After $6 \mathrm{~h}$, the medium was changed and the cells were stimulated with IFN- $\gamma(20 \mathrm{ng} / \mathrm{ml})$ and LPS $(100 \mathrm{ng} / \mathrm{ml})$ as mentioned above for the following experiment. The silencing efficiency was evaluated by RT-qPCR and western blot analysis or ELISA.

Preparation of conditioned medium (CM). To evaluate the antitumor effects of M1 macrophages with different treatments on HCC, we collected the CM as follows: the U937 cells were 
treated with PMA as mentioned above. Following differentiation, the macrophages were washed slightly with PBS and the following additives were added to the medium: PBS served as the control; $20 \mathrm{ng} / \mathrm{ml}$ IFN- $\gamma$ and $100 \mathrm{ng} / \mathrm{ml}$ LPS were used to generate M1 macrophages; siRNA against IRF1 or IFNB1 and negative control siRNA were used prior to IFN- $\gamma / \mathrm{LPS}$ stimulation; $2.7 \mathrm{ng} / \mathrm{ml}$ neutralized monoclonal anti-IFN- $\beta$ monoclonal antibody was used prior to IFN- $\gamma /$ LPS stimulation. The cells were transfected with the siRNA for $6 \mathrm{~h}$ or subjected to anti-IFN- $\beta$ antibody neutralization for $3 \mathrm{~h}$. The medium was removed and the cells were washed with PBS carefully. The cells were then stimulated with IFN- $\gamma /$ LPS for $24 \mathrm{~h}$. The supernatant was collected from 6 groups of cells, labeled as follows: i) CM-control; ii) CM-M1; iii) CM-siRNA control (siC); iv) CM-siRNA against IRF1 (siIRF1); v) CM-siRNA against IFNB1 (siIFNB1); and vi) CM-anti-IFN- $\beta$ antibody (Ab). For culture with $\mathrm{HCC}$ cells, all the $\mathrm{CM}$ were mixed with an equal volume of complete DMEM (80\% DMEM + 20\% FBS + 1\% penicillin and streptomycin).

Cell proliferation assay. To examine the effects of CM on the the proliferation of HCC cells, the viable cells were monitored using the Cell Counting Kit-8 (CCK-8) (Dojindo, Tokyo, Japan). Briefly, the HCC cells were seeded in 96-well plates at a density of $3 \times 10^{3}$ cells/well and were cultured in the different CMs for 24, 48, 72, 96 and $120 \mathrm{~h}$. The viable cells were examined by CCK-8 assay according to the manufacturer's instructions. Five reduplicative wells were used for each group. Each experiment was repeated 3 times.

Analysis of apoptosis. To evaluate the effects of CM on the apoptosis of HCC cells, flow cytometry was applied. Briefly, the SMMC-7721 and HepG2 cells $\left(5 \times 10^{5}\right)$ were cultured in 6 -well plates and treated with different $\mathrm{CM}$ for $72 \mathrm{~h}$. The cells were washed twice with cold PBS after being harvested, and then re-suspended with $400 \mu \mathrm{l}$ cold PBS. Annexin V-FITC and PI (BD Biosciences, San Jose, CA, USA) were added to each well. The cells were incubated in the dark at room temperature for $15 \mathrm{~min}$ and were examined using an influx cell sorter flow cytometer (BD Biosciences) immediately. Each experiment was repeated 3 times.

Transwell invasion assay. To evaluate the effects of CM on the invasion of HCC cells, the Transwell invasion assay was performed using 24-well $8 \mu \mathrm{m}$ pore size Transwell plates (Millipore) coated with Matrigel (1:3 dilution) (BD Biosciences). Briefly, a total of $1 \times 10^{5}$ cells suspended in $200 \mu \mathrm{l}$ serum-free medium containing $0.1 \%$ BSA was added to the upper chamber. The lower chamber was filled with $600 \mu \mathrm{l}$ $\mathrm{CM}$. Following incubation for $24 \mathrm{~h}$, the non-invaded cells in the upper side of the chamber were carefully removed by scraping. The cells that had invaded into the lower side of the chamber were fixed with $0.4 \%$ paraformaldehyde for $20 \mathrm{~min}$ and stained with $0.1 \%$ crystal violet for $10 \mathrm{~min}$. Images were then captured using a Nikon Eclipse 80i microscope (Nikon, Tokyo, Japan) at x100 magnification. Five fields for each group were randomly selected to be subjected to statistical analysis.

Statistical analysis. All experiments were repeated at least 3 times independently. The data are presented as the means \pm standard error of the mean (SEM) in this study. Statistical analyses were performed using SPSS software version 17.0 software (SPSS, Inc., Chicago, IL, USA). An independent sample t-test or one-way ANOVA were used to determine the differences between 2 groups. A value of $\mathrm{P}<0.05$ was considered to indicate a statistically significant difference.

\section{Results}

U937 cells stimulated with IFN- $\gamma$ and LPS readily acquire an M1 status. U937 is a monocytic tumor cell line, which extensively serves as the precursor of macrophages with some specific treatments $(10,35)$. The genetic profile typical of the M1 phenotype, which includes the IL-12p35, IL-12p40, IL-23p19, IL-6 and TNF- $\alpha$ genes, and the M2 cytokine, IL-10, were detected using RT-qPCR. The protein levels of IL-12p70 and IL-10 were detected by ELISA. As expected, the U937 cells stimulated with IFN- $\gamma$ and LPS exhibited a higher mRNA expression of IL-12p35, IL-12p40, IL-23p19, IL-6 and TNF- $\alpha$ than the unstimulated (PMA alone-treated) cells $(\mathrm{P}<0.01$; Fig. 1A). The IFN- $\gamma$ - and LPS-stimulated U937 cells exhibited a higher secretion of IL-12p70 than the PMA-treated cells [not detected (n.d.)] (Fig. 1B). Of note, the M2 associated cytokine, IL-10, was also expressed at higher levels in the IFN- $\gamma$ - and LPS-stimulated cells than in the PMA-treated ones (Fig. 1B).

Furthermore, the surface markers, CD86 (M1-specific) and CD206 (M2-specific), were analyzed by flow cytometry. A higher expression of CD86 was detected in response to IFN- $\gamma$ and LPS stimulation compared to the unstimulated (PMA alonetreated) cells $(\mathrm{P}<0.001$; Fig. 1C and D). However, no significant difference in CD206 expression was observed between the IFN- $\gamma /$ LPS stimulated and unstimulated (PMA alone-treated) U937 cells, and it was poorly expressed in all cell groups (Fig. 1C and D). These data collectively demonstrate that U937 cells can be polarized to an M1 status by stimulation with IFN- $\gamma / \mathrm{LPS}$.

Upregulation of IRF1, IFN- $\beta$ and IRF5 in U937-M1 macrophages. Studies have shown that IRF1 and IFN- $\beta$ are crucial molecules involved in the IFN- $\gamma$ - and LPS-initiated activation of signaling pathways (the IFN- $\gamma / \mathrm{STAT} 1 / \mathrm{IRF} 1$ and LPS/ TLR4/TRAM/TRIF pathways) $(17,18,23)$. Recent studies have also revealed that IRF5 plays a crucial role in the regulation of M1 macrophages $(28,29)$. Therefore, we wished to determine whether these 3 molecules are upregulated in the U937-M1 model. As shown in Fig. 2A, it was observed that the mRNA expression of IRF1, IFNB1 and IRF5 was significantly upregulated by stimulation with IFN $-\gamma$ and LPS $(\mathrm{P}<0.05$ and $\mathrm{P}<0.01)$. IRF1 and IFNB1 exhibited a similar tendency in expression; both reached peak levels at $4 \mathrm{~h}$ of stimulation with IFN- $\gamma$ and LPS. However, IRF5 expression reached peak levels at $6 \mathrm{~h}$. In addition, the protein levels of IFN- $\beta$, IRF1 and IRF5 were examined by ELISA or western blot analysis. Consistent with above-mentioned increase in the mRNA levels, increased protein expression levels of IRF1, IFN- $\beta$ and IRF5 were detected in the IFN- $\gamma /$ LPS-stimulated U937 cells compared with the unstimulated (PMA alone-treated) cells (Fig. 2B and C). Collectively, these results indicate that IRF1, IFN- $\beta$ and IRF5 are upregulated in U937-M1 macrophages. These results prompted us to further investigate the roles they play in the M1 polarization of macrophages and in M1-mediated antitumor effects. 

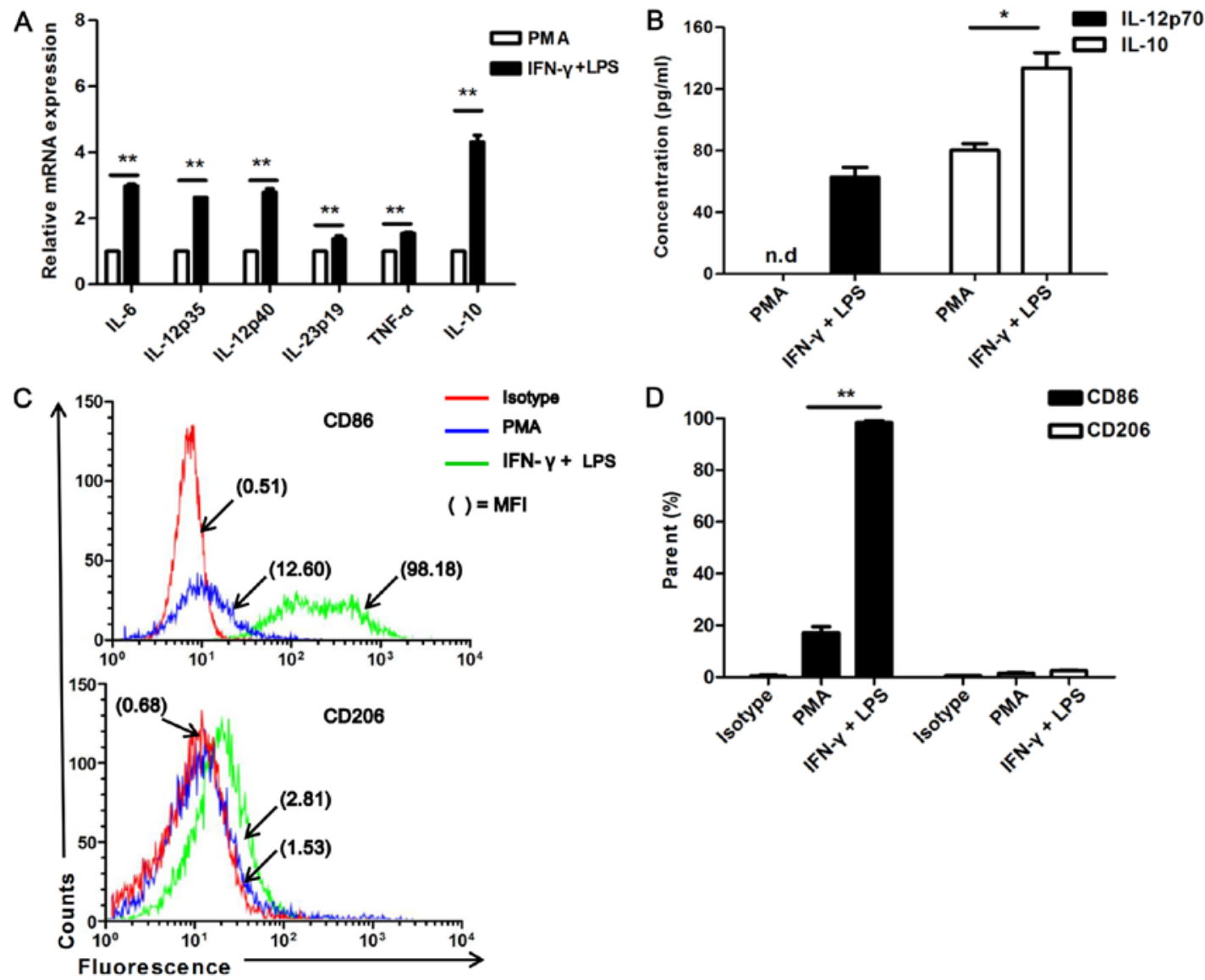

Figure 1. Expression of cytokines and markers of U937-macrophages stimulated with interferon- $\gamma$ (IFN- $\gamma$ ) and lipopolysaccharide (LPS). (A) RT-qPCR analysis of M1-associated genes, including IL-12p40, IL-12p35, IL-23p19, IL-6 and TNF- $\alpha$, and the M2-associated gene, IL-10, in U937 unstimulated (only treated with $5 \mathrm{ng} / \mathrm{ml}$ PMA; labeled as PMA) or stimulated with IFN- $\gamma(20 \mathrm{ng} / \mathrm{ml})$ and LPS $(100 \mathrm{ng} / \mathrm{ml})$ (labeled as IFN- $\gamma+$ LPS $)$ for $8 \mathrm{~h},{ }^{* * *} \mathrm{P}<0.01$. (B) ELISA of the IL-12p70 and IL-10 secretion levels in PMA or IFN- $\gamma+$ LPS group, ${ }^{*} \mathrm{P}<0.05$. (C) The raw flow cytometry fluorescence data are representative of 3 independent experiments for CD86 and CD206 expression; staining profiles of PMA or IFN- $\gamma+$ LPS-stimulated U937 cells. The percentage of positive cells and mean fluorescence intensities (MFIs) are denoted. (D) Histograms shows surface staining for CD86 and CD206 expression on PMA or IFN- $\gamma+$ LPS-stimulated U937 cells, ${ }^{* *} \mathrm{P}<0.001$. Data were calculated from 3 independent experiments.
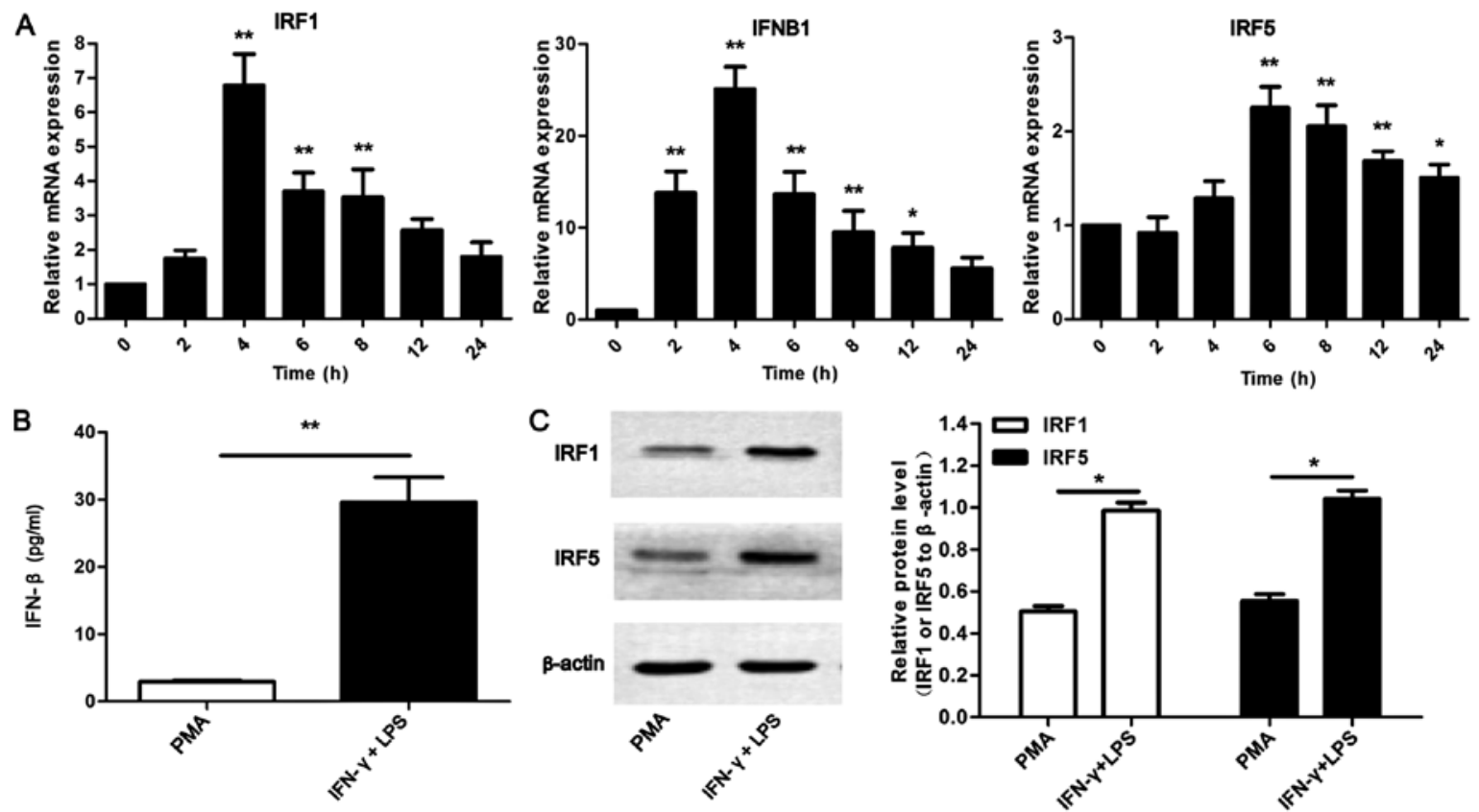

Figure 2. High expression of interferon regulatory factor (IRF)1, interferon- $\beta$ (IFN- $\beta$ ) and IRF5 in M1 macrophages stimulated with interferon- $\gamma$ (IFN- $\gamma$ ) and lipopolysaccharide (LPS). (A) RT-qPCR analysis of IRF1, IFN- $\beta$ and IRF5 mRNA in PMA or IFN- $\gamma+$ LPS stimulated U937 cells for 2, 4, 6, 8, 12 and $24 \mathrm{~h}$. Results are presented relative to those of unstimulated macrophages $(0 \mathrm{~h}),{ }^{*} \mathrm{P}<0.05,{ }^{* * *} \mathrm{P}<0.01$. (B) ELISA of IFN- $\beta$ secretion in supernatant in PMA or IFN- $\gamma+\mathrm{LPS}$ treated U937 cells for $24 \mathrm{~h},{ }^{* * *} \mathrm{P}<0.01$. (C) Western blot analysis of IRF1 and IRF5 in cell lysate from PMA or IFN- $\gamma+\mathrm{LPS}$ treated U937 cells for $24 \mathrm{~h},{ }^{* * *} \mathrm{P}<0.01$. Actin was used as an internal control for both RT-qPCR and western blot analysis. Western blot analysis data were calculated from 3 individual experiments. 


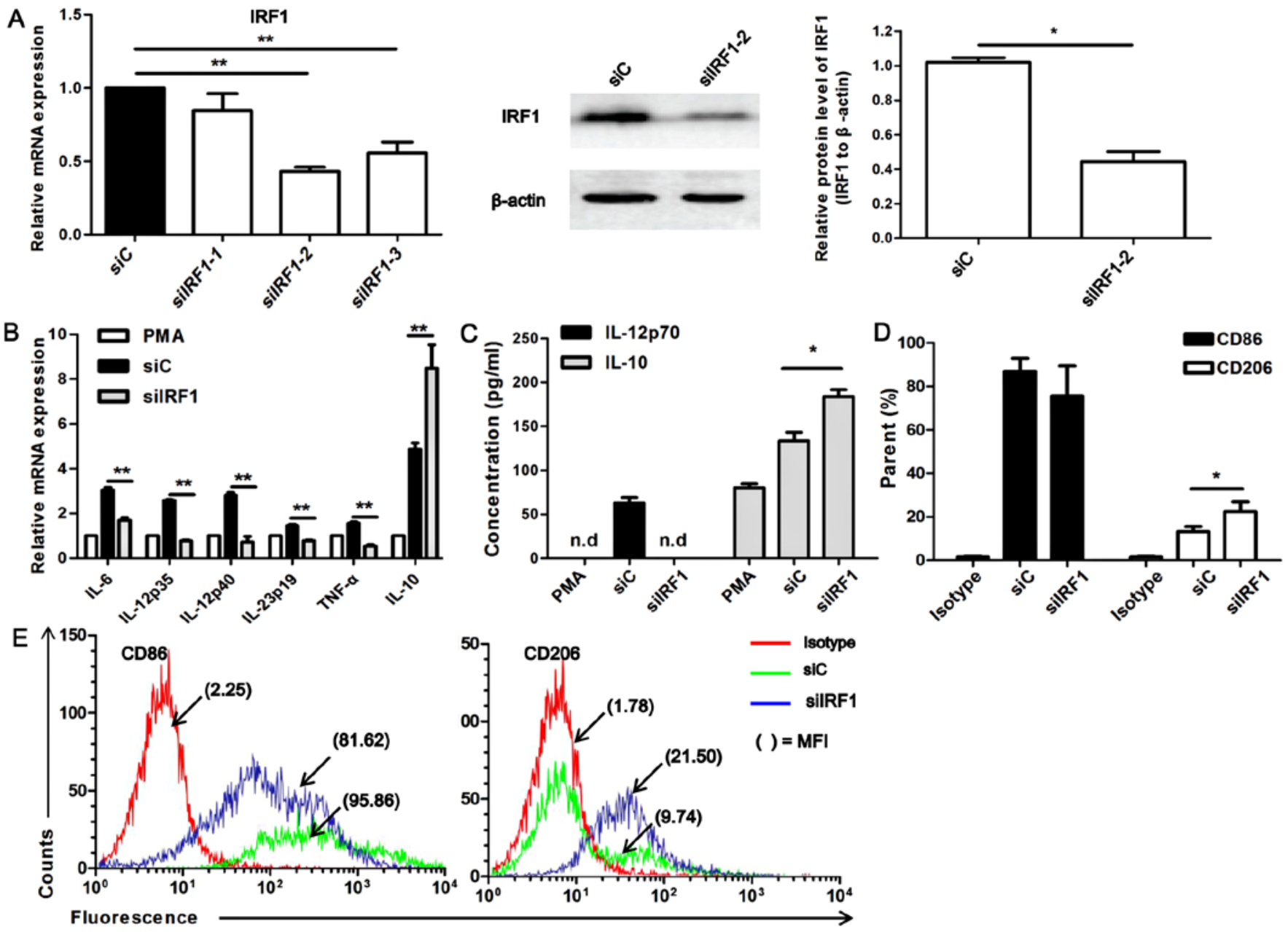

Figure 3. Interferon regulatory factor 1 (IRF1) regulates the expression of macrophage polarization-specific cytokines. (A) RT-qPCR analysis of the silencing efficiency of 3 siRNAs targeting IRF1, ${ }^{* *} \mathrm{P}<0.01$. Western blot analysis of the silencing efficiency of siIRF1-2, ${ }^{*} \mathrm{P}<0.05$. The western blot analysis chart is a representative of 3 independent experiments. (B) RT-qPCR analysis of the mRNA expression of IL-12p40, IL-12p35, IL-23p19, IL-6, TNF- $\alpha$ and IL-10 in M1 macrophages transfected with siIRF1-2 (siIRF1) or the control siRNA (siC), ** P<0.01. (C) ELISA of IL-12p70 and IL-10 secretion in M1 macrophages transfected with siIRF1-2 (siIRF1) or siC, ${ }^{*} \mathrm{P}<0.05,{ }^{* * *} \mathrm{P}<0.01$; n.d, not detected. (D) Histograms showing surface staining for CD86 and CD206 expression on siIRF1- or siC-transfected U937-M1 cells, "P<0.05. Data were calculated from 3 independent experiments. (E) The raw flow cytometry fluorescence data are representative of 3 independent experiments for CD86 and CD206 expression; staining profiles of U937-M1 cells transfected with siIRF1 or siC. The percentage of positive cells and mean fluorescence intensities (MFIs) are denoted.

IRF1 affects U937-M1 macrophage polarization status. Given that IRF1 can be upregulated several fold in IFN- $\gamma$ stimulated macrophages or in dendritic cells (DCs) as opposed to resting DCs or macrophages (20) and given its role in IL-12 regulation (20), and taking our above-mentioned findings into consideration, the role of IRF1 in M1 polarization was investigated following transfection of the cells with siRNA targeteing IRF1 (siIRF1). The silencing efficiency of 3 siIRF1s was determined at the mRNA and protein level by RT-qPCR and western blot analysis (Fig. 3A). siIRF1-2 had the highest silencing efficiency $(\mathrm{P}<0.01)$; thus, siIRF1-2 (termed siIRF1) was used in the following experiments. Marked differences in the levels of phenotypic markers were observed between the siIRF1-transfected U937-M1 macrophages and the siC (control)-transfected cells (Fig. 3B). The siIRF1-transfected U937-M1 cells exhibited a generally downregulated expression of M1 genes, including IL-12p35, IL-12p40, IL-23p19, IL-6 and TNF- $\alpha$, but an enhanced expression of the M2 gene, IL-10, compared with the siC-transfected U937-M1 cells $(\mathrm{P}<0.01$; Fig. 3B). Furthermore, we detected the amount of IL-12p70 and IL-10 secreted in supernatant by ELISA, and observed that upon IRF1 knockdown, no production of IL-12p70 was detected. However, an enhanced production of IL-10 was observed in the siIRF1-transfected U937-M1 macrophages compared to the siC-transfected U937-M1 cells ( $\mathrm{P}<0.05$; Fig. 3C).

Moreover, the M1-specific marker, CD86, and the M2-specific marker, CD206, were analyzed by flow cytometry. As shown in Fig. 3D and E, an increased expression of CD206 was detected in the siIRF1-transfected U937-M1 cells compared with siC-transfected U937-M1 cells $(\mathrm{P}<0.05$; Fig. 3D and E). Although the reduction in CD86 expression did not reach a level of significance between the siIRF1-transfected M1 macrophages and the siC-transfected M1 macrophages, an obvious decreasing trend in its expression was observed in the siIRF1-transfected M1 macrophages. These data suggest that IRF1 is involved in the M1 polarization of macrophages, as indicated by the expression of M1/M2-associated markers and cytokines.

Inhibition of IFN- $\beta$ affects the MI status induced by stimulation with IFN- $\gamma$ and LPS. A recent study reported that 

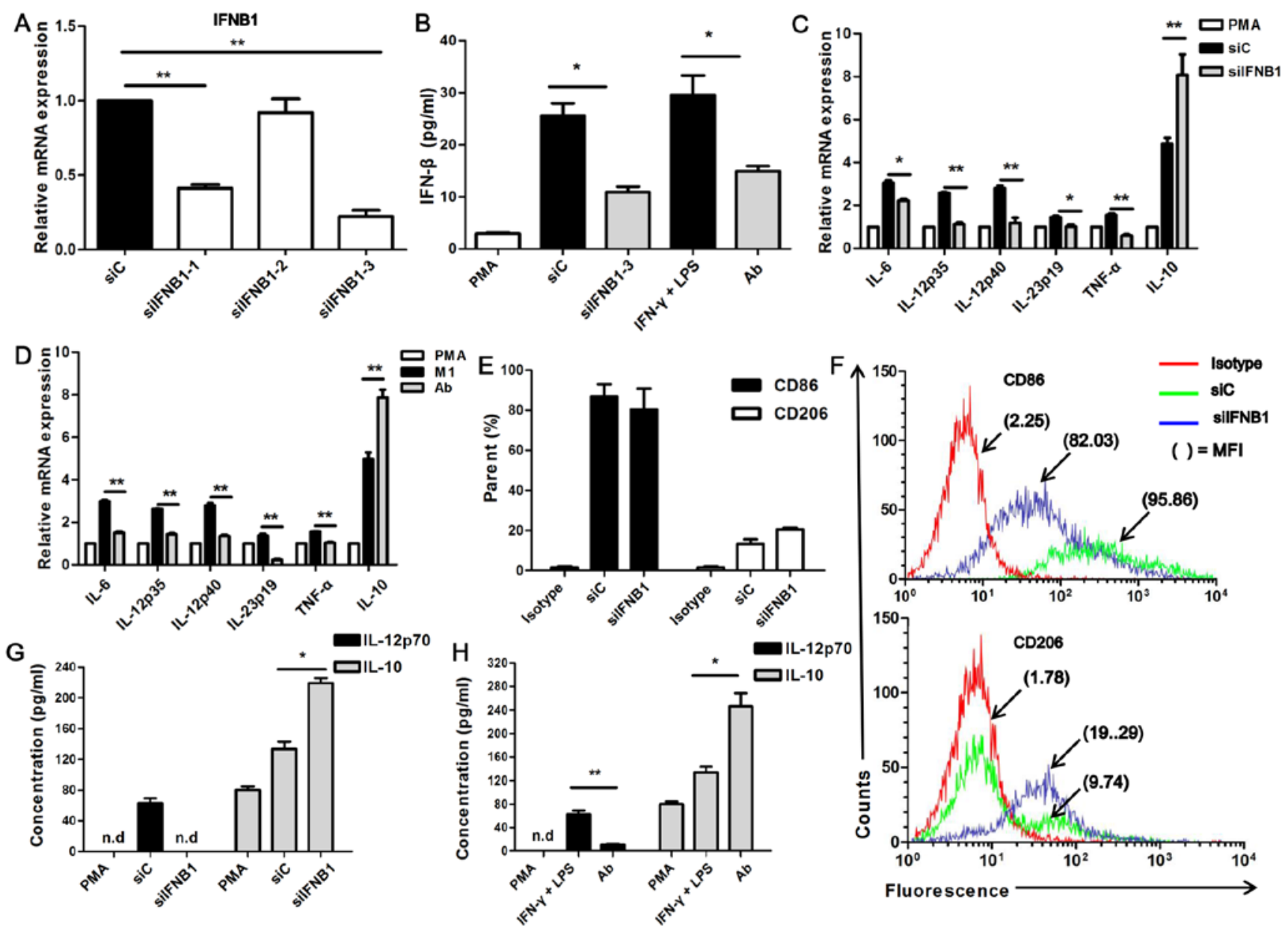

Figure 4. Interferon- $\beta$ (IFN- $\beta$ ) affects the expression of macrophage polarization-specific cytokines. (A) RT-qPCR analysis of the silencing efficiency of siIFNB1, ${ }^{* *} \mathrm{P}<0.01$. (B) ELISA of the silencing efficiency of siIFNB1-3 or neutralizing efficiency of anti-IFN- $\beta,{ }^{*} \mathrm{P}<0.05$. (C and D) RT-qPCR analysis of mRNA expression of IL-12p40, IL-12p35, IL-23p19, IL-6, TNF- $\alpha$, and IL-10 in M1 macrophages transfected with siIFNB1-3 (siIFNB1) or siC, or neutralized with anti-IFN- $\beta$ antibody (Ab), ${ }^{*} \mathrm{P}<0.05,{ }^{* *} \mathrm{P}<0.01$. (E) Histograms showing surface staining for CD86 and CD206 expression on siIFNB1- or siC-transfected U937-M1 cells. Data were calculated from 3 independent experiments. (F) The raw flow cytometry fluorescence data are representative of 3 independent experiments for CD86 and CD206 expression on U937-M1 transfected with siIFNB1 or siC. The percentage of positive cells and mean fluorescence intensities (MFIs) are denoted. $(\mathrm{G}$ and $\mathrm{H})$ ELISA of the IL-12p70 and IL-10 secretion by M1 macrophages transfected with siIFNB1 or siC or neutralized with anti-IFN- $\beta$ antibody. Data were calculated from 3 independent experiments. ${ }^{*} \mathrm{P}<0.05,{ }^{* *} \mathrm{P}<0.01$; n.d, not detected.

IFN- $\beta$ is expressed in high levels in classically polarized macrophages [(THP-CAM) (M1)], whereas it is expressed in low levels in alternatively activated macrophages [(THPAAM) (M2)] (37). It has also been demonstrated that the expression of the M1-specific marker, IL-12p70, is impaired in IFNAR $1^{--}$GM-BMM (M1), and is enhanced by exogenous IFN- $\beta$ in GM-BMM (24). In this study, we inhibited IFN- $\beta$ with anti-IFN- $\beta$ neutralizing antibody or siRNA targeting the IFNB1 gene (siIFNB1). The neutralizing and silencing efficiency were examined by RT-qPCR and ELISA, respectively (Fig. 4A and B). We found that siIFNB1-3 had the highest silencing efficiency $(\mathrm{P}<0.001$; Fig. $4 \mathrm{~A})$; thus, siIFNB1-3 (termed siIFNB1) was used in the following experiments. The secretion level of IFN- $\beta$ was decreased in the siIFNB1-transfected U937-M1 cells and in the cells in which IFN $-\beta$ had been neutralized $(\mathrm{Ab})$ compared with the control siRNA (siC)-transfected U937-M1 cells ( $\mathrm{P}<0.05$; Fig. 4B). It was observed that with the use of either siIFNB1 or IFN- $\beta$ neutralizing antibody $(\mathrm{Ab})$, the U937-M1 cells exhibited a significantly reduced expression of M1-associated genes, including IL-12p35, IL-12p40, IL-23p19, IL-6 and TNF- $\alpha$, but an enhanced expression of the M2-associated gene, IL-10, compared with the siC-transfected U937 cells $(\mathrm{P}<0.05$ and $\mathrm{P}<0.01$; Fig. 4C and D). As regards IL-12p70, its secretion was significantly decreased in the IFN- $\beta$-neutralized U937-M1 cells, and its secretion levels were even undetectable in the siIFNB1-transfected U937-M1 cells. However, as regards IL-10, its secretion was increased by 2 -fold in the IFN- $\beta$ neutralized U937-M1 cells and in the siIFNB1-transfected U937-M1 cells compared with the siC-transfected and IFN- $\gamma /$ LPS-stimulated U937-M1 cells ( $\mathrm{P}<0.05$ and $\mathrm{P}<0.01$; Fig. 4G and $\mathrm{H}$ ).

The expression of CD86 and CD206 did not reach a level of significance between the siIFNB1-transfected M1 and the siC-transfected M1 macrophages; however, an obvious increasing trend in CD206 expression and a decreasing trend in CD86 expression was observed in the siIFNB1-transfected M1 macrophages (Fig. 4E and F). The impaired expression of M1-associated markers and the enhanced expression of M2-associated markers observed following the inhibition of IFN- $\beta$ in the U937-M1 macrophages suggests that endogenous IFN- $\beta$ is required to maintain the M1 polarization status. 

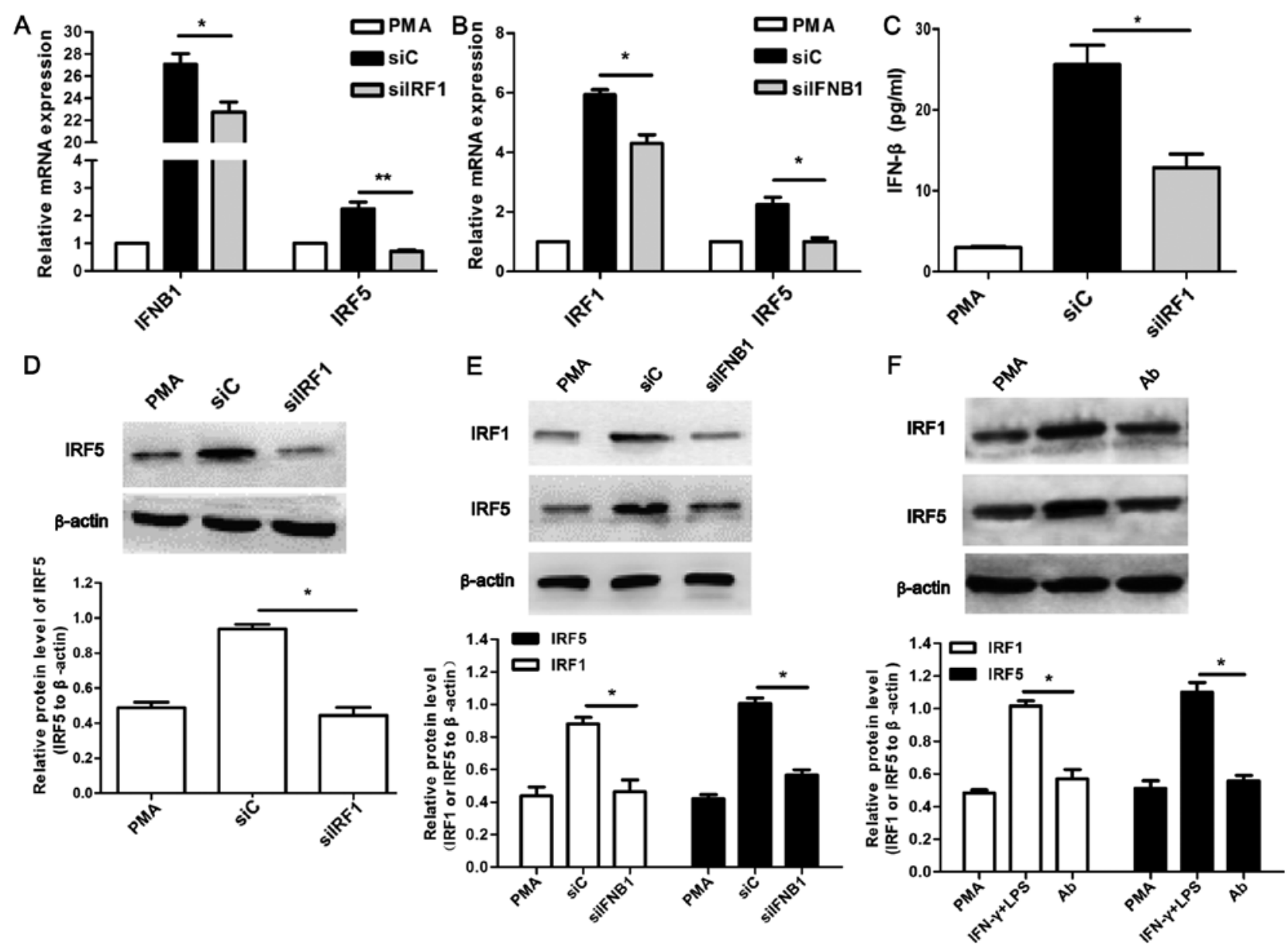

Figure 5. Cooperation between interferon regulatory factor (IRF) 1 and interferon- $\beta$ (IFN- $\beta$ ) in U937-M1 macrophages. (A) Analysis of IFNB1 and IRF5 by RT-qPCR in M1 macrophages transfected with siIRF1 or siC. (B) Analysis of IRF1 and IRF5 by RT-qPCR in M1 macrophages transfected with siIFNB1 or siC. (C) Analysis of IFN- $\beta$ by ELISA in M1 macrophages transfected by siIRF1. (D-F) Analysis of IRF1 and IRF5 by western blot analysis in M1 macrophages transfected with siIRF1, siIFNB1, siC or neutralized with anti-IFN- $\beta$ antibody (Ab). ${ }^{*} \mathrm{P}<0.05,{ }^{* *} \mathrm{P}<0.01$. Western blots are representative of 3 individual experiments.

Association between IRF1 and IFN- $\beta$ in the regulation of $M 1$ polarization. To further investigate the underlying mechanism of M1 polarization associated with IRF1 and IFN- $\beta$, the expression of IFN- $\beta$ in the siIRF1-transfected U937-M1 cells was detected. The expression of IRF1 in the IFN- $\beta$-neutralized U937-M1 was also examined. As shown in Fig. 5A and C, the siIRF1-transfected U937-M1 cells exhibited a decreased expression of IFN- $\beta$ at both the mRNA and protein level $(\mathrm{P}<0.05)$. Concordantly, the decreased expression of IRF1 at both the mRNA and protein level was observed in the siIFNB1-transfected U937-M1 cells $(\mathrm{P}<0.05$; Fig. 5B and E) and in the IFN- $\beta$-neutralized (Ab) U937-M1 cells (Fig. 5F).

Furthermore, the decreased mRNA and protein expression of IRF5 was observed in the U937-M1 cells in which IRF1 was inhibited $(\mathrm{P}<0.05$; Fig. 5A and D). Surprisingly, we observed similar results with the expression of IRF5 in the cells in which IFN- $\beta$ was inhibited $(\mathrm{P}<0.05$; Fig. $5 \mathrm{~B}, \mathrm{E}$ and $\mathrm{F})$.

Therefore, these results suggest that IRF1 and IFN- $\beta$ interact with each other, which bridges the signaling pathways activated by IFN $-\gamma$ and LPS in M1 polarized macrophages. Furthermore, both IRF1 and IFN- $\beta$ may regulate the expression of IRF5, which in turn contributes to the M1 polarization of macrophages. However, the detailed mechanisms involved require further investigation.
IRF1 and IFN- $\beta$ play significant roles in M1-mediated antitumor effects. Several studies have demonstrated that, M1 macrophages can combat tumors. They can suppress proliferation, prevent invasion and promote the apoptosis of cancer cells through the secretion of certain cytokines (45-49). Our observation of the impaired M1 status (as shown above) promoted us to investigate whether M1-mediated antitumor effects would be affected under such treatment conditions. HepG2 and SMMC-7721 cells were cultured with various CM. The M1-mediated antitumor effects were then examined with respect to proliferation, apoptosis and invasion ability.

To examine the effects of various $\mathrm{CM}$ on the proliferation of HCC cells, CCK-8 assay was performed. As shown in Fig. 6, CM collected from the M1 macrophages (CM-M1) and siC-transfected M1 macrophages (CM-siC) significantly inhibited the proliferation of HepG2 cells $(\mathrm{P}<0.05$; Fig. 6A and $\mathrm{B}$ ) and SMMC-7721 ( $\mathrm{P}<0.05$; Fig. 6C and D). By contrast, the $\mathrm{CM}$ collected from M1 macrophages in which IRF1 or IFN- $\beta$ was inhibited (CM-siIRF1, CM-siIFNB1 or CM-Ab) partly restored the proliferation of SMMC-7721 cells $(\mathrm{P}<0.05$; Fig. 6C and D), and even promoted the proliferation of HepG2 cells $(\mathrm{P}<0.05$; Fig. $6 \mathrm{~A}$ and $\mathrm{B})$. These data suggest that IRF1 and IFN- $\beta$ play important roles in the M1-mediated antiproliferative effects on HCC cells. 

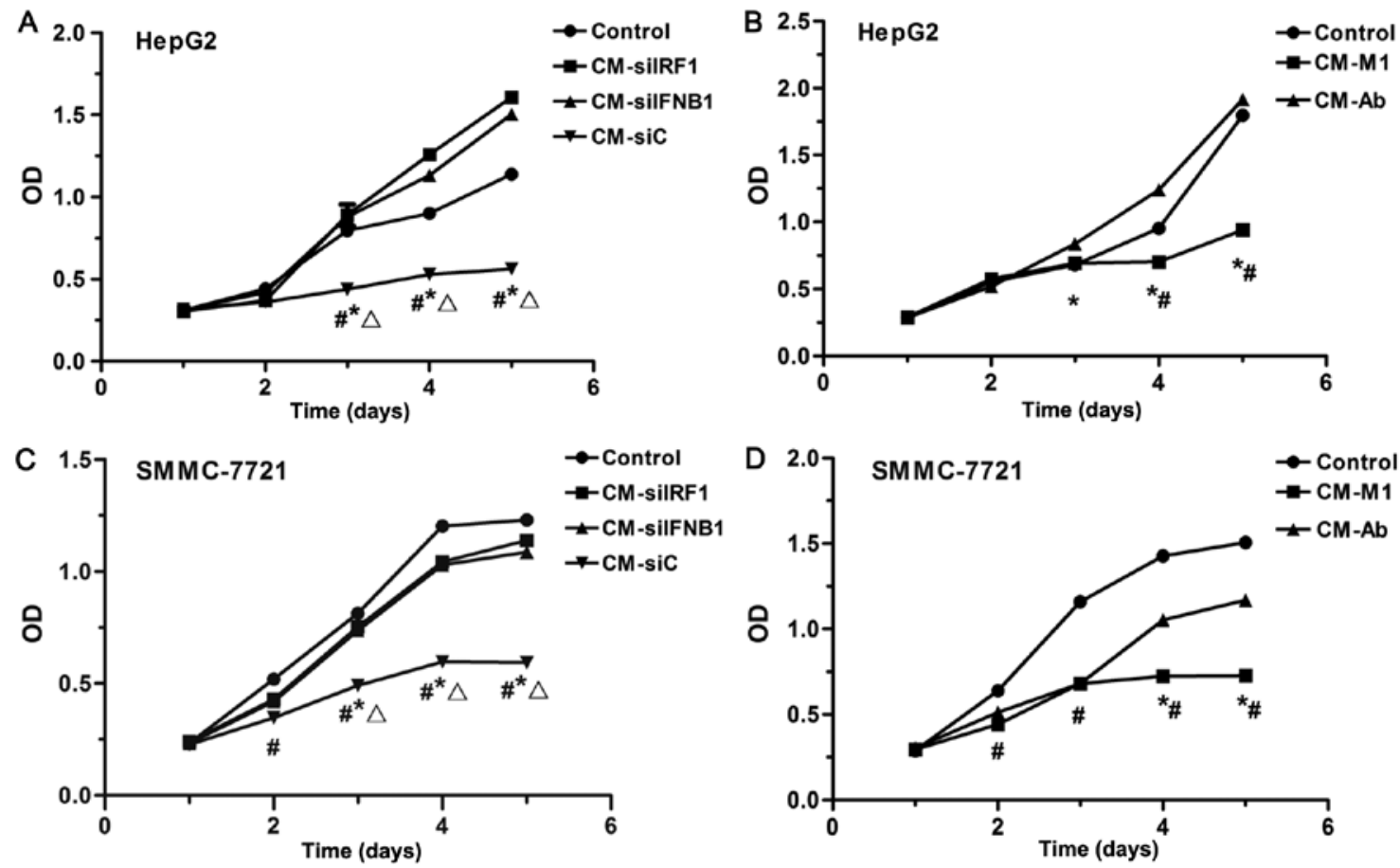

Figure 6. Effect of conditioned medium (CM) on the M1-mediated anti-proliferative effects on hepatoma carcinoma (HCC) cells. CCK-8 proliferation assay of (A and B) HepG2 cells and (C and D) SMMC-7721 cells incubated with different $\mathrm{CM}$ for 1 to 5 days. (A and C) ${ }^{\#} \mathrm{P}<0.05$, control vs. CM-siC, (B and D) control vs. CM-M1; (A and C) ${ }^{*} \mathrm{P}<0.05$, CM-siIFNB1 vs. CM-siC, (B and D) CM-Ab vs. CM-M1; (A and C) ${ }^{\triangle} \mathrm{P}<0.05$, CM-siIRF1 vs. CM-siC. Data were calculated from 3 independent experiments.

Flow cytometry was performed to determine the effects of IRF1 and IFN- $\beta$ on the apoptosis of HCC cells. As shown in Fig. 7, an increased apoptotic rate was observed in the cells cultured with CM-M1 and CM-siC compared the control cells cultured with DMEM (HepG2 cells, $\mathrm{P}<0.05$; Fig. 7B; and SMMC-7721 cells, P<0.01; Fig. 7D). However, the pro-apoptotic effect was partly inhibited in the SMMC-7721 cells cultured with CM-siIRF1 or CM-siIFNB1 or CM-Ab $(\mathrm{P}<0.01$; Fig. 7D). Although the apoptosis of the HepG2 cells did not reach a level of significance between the cells cultured with $\mathrm{CM}$-siC vs. CM-siIFNB1 $(\mathrm{P}=0.056)$ and $\mathrm{CM}$-siC vs. $\mathrm{CM}$-siIRF1 ( $\mathrm{P}=0.065)$, an obvious decreasing trend in apoptosis was observed in the HepG2 cells cultured with M1 cells in which IFNB1 and IRF1 was inhibited compared with the controls (Fig. 7B). These data indicate that IRF1 and IFN- $\beta$ may play a role in the M1-mediated pro-apoptotic effects on HCC cells.

The invasion ability was examined by Transwell invasion assay. As shown in Fig. 8, in the HCC cells cultured with CM-M1 and CM-siC, the number of invading cells was significantly reduced compared with the control cells cultured in DMEM (P<0.01; HepG2, Fig. 8B; SMMC-7721, Fig. 8D). By contrast, these inhibitory effects on the invasion of HCC cells were completely reversed in the HCC cells cultured with CM-siIRF1, CM-siIFNB1 or CM-Ab (P<0.01; HepG2, Fig. 8B; SMMC-7721, Fig. 8D). These data suggest that IRF1 and IFN- $\beta$ contribute to the M1-mediated inhibitory effects on the invasion ability of HCC cells.

Collectively, the results of our above-mentioned experiments suggest that U937-M1 macrophages exert tumoricidal effects against HepG2 and SMMC-7721 cells, and we further identi- fied the crucial roles of IRF1 and IFN- $\beta$ in the M1-mediated antitumor effects.

\section{Discussion}

Macrophages display remarkable plasticity and undergo alterations in their phenotypes in response to distinct environmental cues (1). Two major subsets, including classically activated (M1) and alternatively activated (M2) macrophages, have long been recognized $(3,4,38)$. They can play contrasting roles in tumorigenesis depending on the different phenotypes. It has been well established that M1 macrophages possess antitumor properties, whereas M2 macrophages are characterized by pro-tumor effects $(14,15,39)$. Therefore, a comprehensive understanding of the underlying mechanisms of macrophage polarization is necessary for developing antitumor strategies.

Several signaling pathways related to the polarization of macrophages have been identified. A major locus for macrophage polarization is at the transcriptional level of regulation. The key regulators, including STAT1, activator protein 1 (AP1), IRF1/3/5/9 and hypoxia-inducible factor (HIF)- $1 \alpha$, play crucial roles in the M1 polarization of macrophages. Other modulators, such as STAT6, peroxisome proliferator-activated receptor (PPAR)- $\gamma$, IRF4, HIF-2 $\alpha$, Kruppel-like factor 4 (KLF4) and CCAAT-enhancer-binding protein $(\mathrm{C} / \mathrm{EBP}) \beta$ play a significant role in the M2 polarization of macrophages $(16,40)$.

Interestingly, it has been revealed that synergistic stimulation with IFN- $\gamma$ and LPS is necessary for the polarization of human M1 macrophages, as oppposed to stimulation with either factor alone (27). Thus, it is necessary to explore the underlying 
A
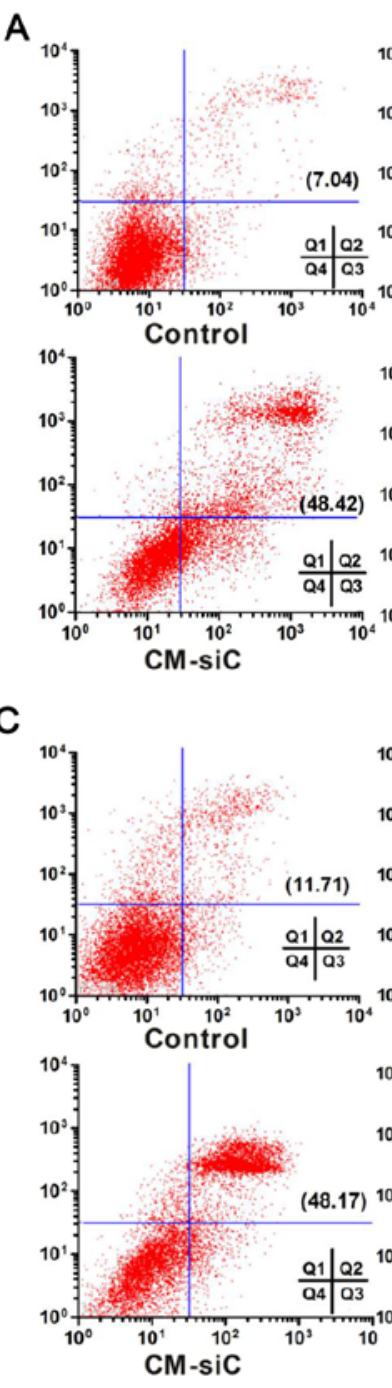
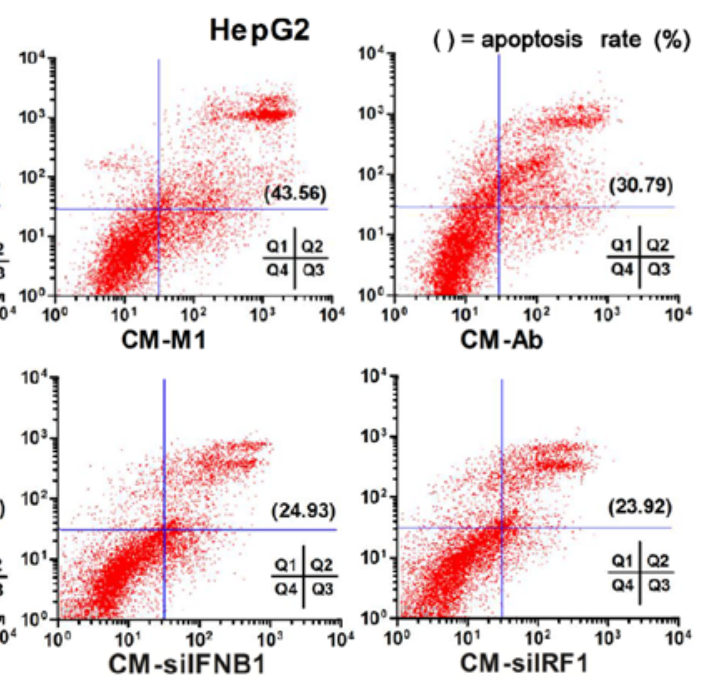

SMMC-7721
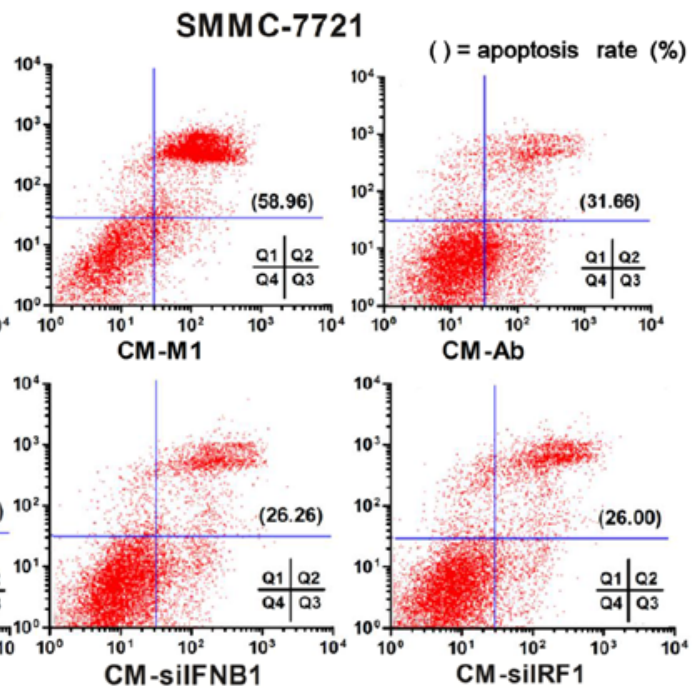

\section{B}

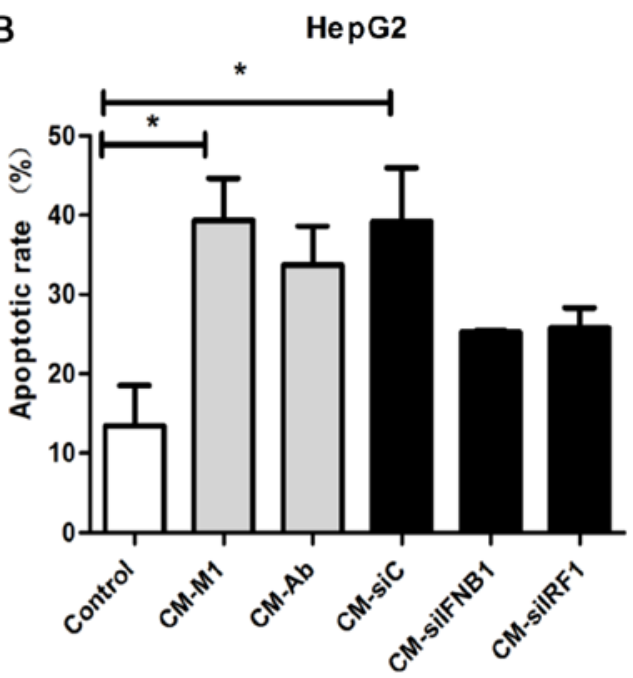

D

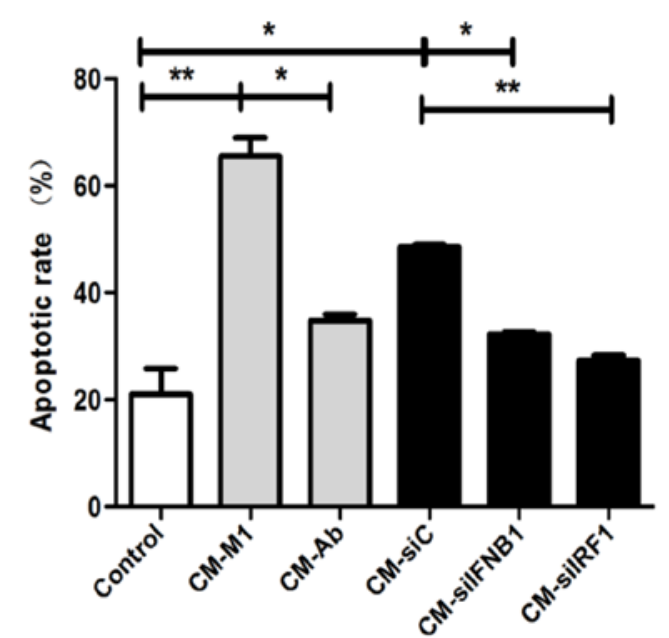

Figure 7. Effect of conditioned medium (CM) on the M1-mediated pro-apoptotic effect on hepatoma carcinoma (HCC) cells. (A and C) The raw flow cytometry scatter plots are representative of 3 independent experiments for apoptosis of (A) HepG2 cells and (C) SMMC-7721 cells cultured with CMs. The numbers in parentheses represent the apoptotic rate (quadrant 2 plus quadrant 3). (B and D) Histograms showing the apoptotic rate of (B) HepG2 cells and (D) SMMC-7721 cells cultured with CMs, ${ }^{*} \mathrm{P}<0.05$. Data were repeated for 3 independent experiments.

mechanisms of the M1 polarization of macrophages under the synergistic effects of IFN- $\gamma$ and LPS.

IRFs are transcriptional mediators, which can be induced by bacteria or viruses. In mammals, IRFs consist of 9 members, including IRF1, IRF2, IRF3, IRF4, IRF5, IRF6, IRF7, IRF8 (ICSBP) and IRF9 (ISGF3 $\gamma / \mathrm{p} 48$ ). They play prominent roles in antiviral defense, immune response, tumor suppression, SLE susceptibility, cell differentiation and apoptosis (40-42). In particular, IRF $1 / 5 / 8$ has been shown too regulate the M1 polarization of macrophages, whereas IRF4 is involves in M2 polarization (43). The mechanisms of macrophage polarization as regards IRFs are not yet fully understood.

It has been reported that IRF1 can be induced by IFN- $\gamma$ in M1 macrophages (19), and that it is responsible for the expression of M1-associated cytokine IL-12 subunits and iNOS $(20,21)$. On the other hand, the production of IFN- $\beta$ is dependent on the LPS-induced activation of the TRIFdependent pathway (23). Furthermore, it has been demonstrated that endogenous IFN- $\beta$ is also necessary for the production of
IL-12p70 in GM-BMM $(20,24)$. It has also been revealed that IFN- $\beta$ is expressed in high levels in THP-M1 macrophages, whereas it is expressed in low levels in THP-M2 macrophages (37). We noted that IRF1 was originally discovered to regulate the transcription of IFN- $\beta$ in fibroblasts infected with virus (25). However, the connection between IRF1 and IFN- $\beta$ in M1 macrophages is not yet well clarified.

To address this issue, we referred to several studies in the literature $(10,16,35)$, and established the M1 macrophage model with the monocytic tumor cell line, U937 (U937-M1) in the present study. The results demonstrated that U937 cells could be readily polarized into the $\mathrm{M} 1$ status, as indicated by the high expression of CD86 and several pro-inflammatory cytokines, but the low expression of CD206. Surprisingly, we noted that the M2 associated cytokine, IL-10, was also upregulated in U937-M1 macrophages. Although there has been some controversy, IL-10 is generally considered an M2-associated cytokine marker $(4,5,8,9)$. It has been previously reported that IFN- $\gamma$ and LPS stimulate macrophages to produce IL-10 $(8,44)$. We specu- 
A

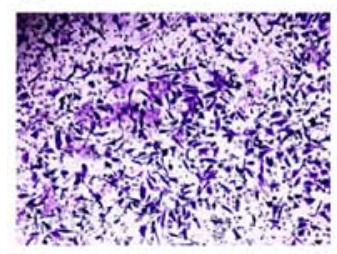
Control

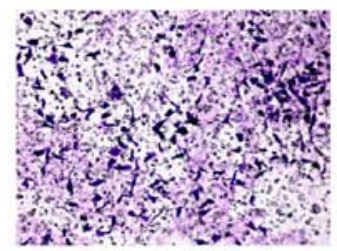

CM-siC

$\mathrm{C}$

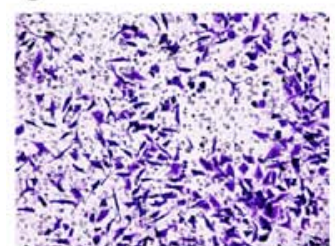
Control

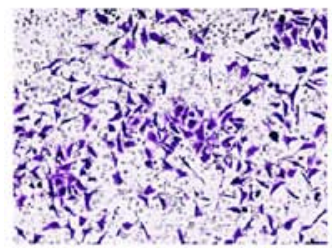

CM-siC
HepG2

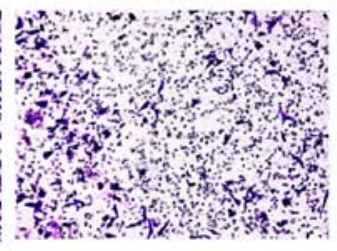

CM-M1

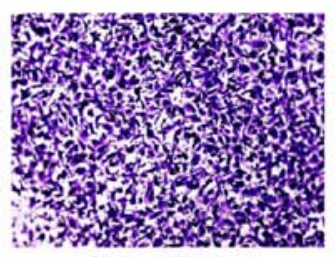

CM-silFNB1

SMMC-7721

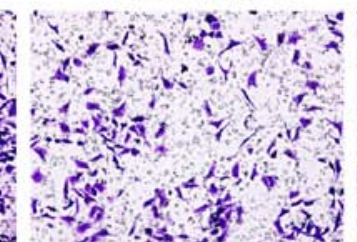

CM-M1

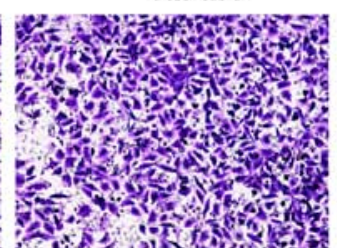

CM-silFNB1

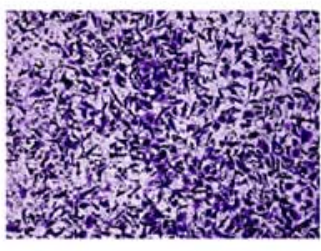

CM-Ab

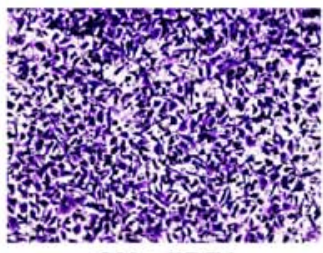

CM-silRF 1

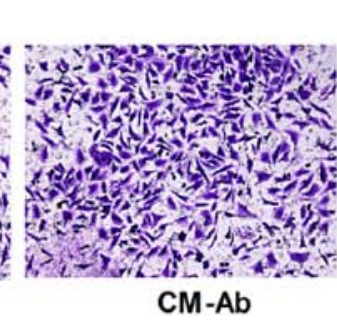

B

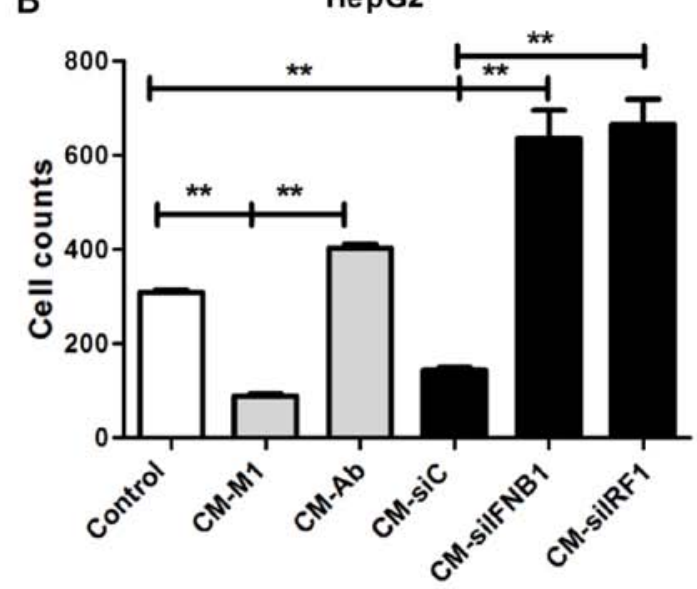

D

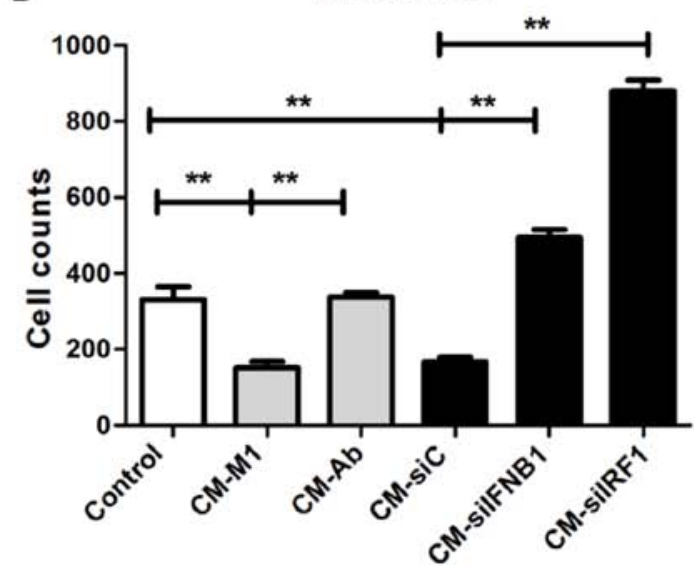

Figure 8. Effect of conditioned medium (CM) on the M1-mediated anti-invasion effect on hepatoma carcinoma (HCC) cells. Invasive ability was analyzed by Transwell invasion assay. HepG2 and SMMC-7721 cells were cultured with various CM for 24 h, and the invading cells were fixed and stained, then counted under a microscope with 5 random fields (x100 magnification). (A) The data are representative of 5 random fields of HepG2 cells cultured with CMs; (B) Histograms showing invading cells of HepG2 cells cultured with $\mathrm{CMs},{ }^{* *} \mathrm{P}<0.01$. Data were repeated for 3 independent experiments. (C) The data are representative of 5 random fields of SMMC-7721 cells cultured with CMs;(D) Histograms showing invading cells of SMMC-7721 cells cultured with CMs, ${ }^{* *} \mathrm{P}<0.01$. Data were calculated from 3 independent experiments.

late that IL-10, as an anti-inflammatory cytokine, may play a role in the resolution of inflammation to avoid the M1-mediated excessive pro-inflammatory response.

The present study indicated that IRF1 and IFN- $\beta$ play crucial roles in the regulation of the M1 polarization of macrophages. In the M1 macrophages in which the IRF1 gene was silenced, not only IL-12 production was impaired, but also the expression of other pro-inflammatory cytokines, such as IL-6, IL-23p19, and TNF- $\alpha$. Simultaneously, IFN- $\beta$ played a similar role as IRF1 in M1-associated gene regulation, which was investigated by the use of siRNA and neutralizing monoclonal IFN- $\beta$ antibody. Interestingly, the M2-associated markers, CD206 and IL-10, were further significantly increased in the M1 macrophages in which IRF1 or IFN- $\beta$ was inhibited. These results collectively indicate that both IRF1 and IFN- $\beta$ affect the expression of M1/M2-associated markers, which in turn may affect the M1 polarization of macrophages.

It has been reported that IRF1 regulates certain genes by binding to the IRF-E and ISRE sites (32), such as IRF5 (31) and $I F N-\beta(25,32)$. As a cytokine, IFN- $\beta$ plays a functional role mainly by binding to its receptor on the cell membrane and initiating downstream signaling. It has also been found that IFN- $\beta$ induces IRF1 expression in RAW264.7 and peritoneal macrophages through receptor recognized pathways (26). Based on this evidence, we investigated the association between IRF1 and IFN- $\beta$ in the context of the M1 polarization of macrophages. We found that the knockdown of IRF1 in U937-M1 cells exhibited reduced the production of IFN- $\beta$. Similarly, the neutralization of IFN- $\beta$ or IFNB1 knockdown in U937-M1 cells led to a decreased expression of IRF1. These data suggest that IRF1 and IFN- $\beta$ may interact with each other, which bridges the two pathways initiated by IFN- $\gamma$ and LPS in M1 macrophages.

What should be noted is that our detected M1/M2-associated cytokines (IL-12p35, IL-12p40, IL-23p19, IL-6, TNF- $\alpha$ and IL-10) are also regulated by IRF5. It has been demonstrated that IRF5 is directly recruited to the promoters and promotes the expression of M1-associated genes, but suppresses M2-associated gene expression (28-30). In the current study, IRF5 was upregulated by the stimulation of U937-M1 cells with IFN- $\gamma$ and LPS. To determine whether IRF5 plays a role in IRF1- and IFN- $\beta$-associated activities, we detected IRF5 expression in U937-M1 cells in which IRF1 or IFN- $\beta$ was inhibited. Interestingly, IRF5 was impaired in the U937-M1 
in which IRF1 or IFN- $\beta$ was inhibited. These observations suggest that IRF5 is involved in IRF1- and IFN- $\beta$-mediated activities. The association between IRF1, IFN- $\beta$ and IRF5 may involve more complex mechanisms of the M1 polarization of macrophages. Thus, further studies are warranted to investigate the detailed mechanisms.

In this study, the role of IRF1 and IFN- $\beta$ in M1-mediated antitumor effects on HCC cells was also explored. HepG2 and SMMC-7721 cells were incubated with CM collected from the supernatant of M1 macrophages in which IRF1 or IFN- $\beta$ was inhibited. The results demonstrated that U937-M1 macrophages exerted anti-tumor effects on HepG2 and SMMC-7721 cells, including anti-proliferative, pro-apoptotic and antiinvasive effects. However, the inhibition of IRF1 or IFN- $\beta$ in the U937-M1 macrophages attenuated these antitumor effects. Our functional experiments further proved that IRF1 and IFN- $\beta$ play significant roles in the antitumor effects mediated by M1 macrophages. We speculate that the IRF1- and IFN- $\beta$ mediated antitumor effects may due to the regulation of M1/ M2-associated cytokines, which have been reported to responsible for antitumor/pro-tumor effects (45-49).

In conclusion, in the present study, we provide evidence that IRF1 and IFN- $\beta$ may cooperate with each other to take part in the M1 polarization of macrophages, as well as in the regulation of IRF5, consequently affecting the M1-mediated antitumor effects. Our data may provide a novel target for targeted cancer therapy.

\section{Acknowledgements}

This study was supported by the National Natural Science Foundation of China (grant no. 81172016). We would like to thank Dr Jian Zhang, Dr Shengkai Yan, Dr Shengxiang Ge and Dr Keyang Chen for their valuable suggestions.

\section{References}

1. Das A, Sinha M, Datta S, Abas M, Chaffee S, Sen CK, Roy S: Monocyte and macrophage plasticity in tissue repair and regeneration. Am J Pathol 185: 2596-606, 2015. doi: 10.1016/j. ajpath.2015.06.001.

2. Murray PJ and Wynn TA: Protective and pathogenic functions of macrophage subsets. Nat Rev Immunol 11: 723-737, 2011.

3. Lawrence $T$ and Natoli G: Transcriptional regulation of macrophage polarization: enabling diversity with identity. Nat Rev Immunol 11: 750-761, 2011.

4. Mosser DM and Edwards JP: Exploring the full spectrum of macrophage activation. Nat Rev Immunol 8: 958-969, 2008.

5. Duluc D, Corvaisier M, Blanchard S, Catala L, Descamps P, Gamelin E, Ponsoda S, Delneste Y, Hebbar M and Jeannin P: Interferon-gamma reverses the immunosuppressive and protumoral properties and prevents the generation of human tumor-associated macrophages. Int J Cancer 125: 367-373, 2009.

6. Labonte AC, Tosello-Trampont AC and Hahn YS: The role of macrophage polarization in infectious and inflammatory diseases. Mol Cells 37: 275-285, 2014

7. Chistiakov DA, Bobryshev YV, Nikiforov NG, Elizova NV, Sobenin IA and Orekhov AN: Macrophage phenotypic plasticity in atherosclerosis: the associated features and the peculiarities of the expression of inflammatory genes. Int J Cardiol 184: 436-445, 2015.

8. Melton DW, McManus LM, Gelfond JA and Shireman PK: Temporal phenotypic features distinguish polarized macrophages in vitro. Autoimmunity 48: 161-176, 2015.

9. Biswas SK and Mantovani A: Macrophage plasticity and interaction with lymphocyte subsets: cancer as a paradigm. Nat Immunol 11: 889-896, 2010.
10. Chabot S, Charlet D, Wilson TL, Yong VW and Yong VW: Cytokine production consequent to T cell - microglia interaction: the PMA/IFN gamma-treated U937 cells display similarities to human microglia. J Neurosci Methods 105: 111-120, 2001.

11. Dall'Asta M, Derlindati E, Ardigò D, Zavaroni I, Brighenti $F$ and Del Rio D: Macrophage polarization: The answer to the diet/inflammation conundrum? Nutr Metab Cardiovasc Dis 22: 387-392, 2012.

12. Ohashi W, Hattori K and Hattori Y: Control of macrophage dynamics as a potential therapeutic approach for clinical disorders involving chronic inflammation. J Pharmacol Exp Ther 354: 240-250, 2015.

13. Heusinkveld M and van der Burg SH: Identification and manipulation of tumor associated macrophages in human cancers. J Transl Med 9: 216, 2011.

14. Bögels M, Braster R, Nijland PG, Gül N, van de Luijtgaarden W, Fijneman RJ, Meijer GA, Jimenez CR, Beelen RH and van Egmond M: Carcinoma origin dictates differential skewing of monocyte function. OncoImmunology 1: 798-809, 2012.

15. Pollard JW: Macrophages define the invasive microenvironment in breast cancer. J Leukoc Biol 84: 623-630, 2008.

16. Tugal D, Liao $X$ and Jain MK: Transcriptional control of macrophage polarization. Arterioscler Thromb Vasc Biol 33: 1135-1144, 2013.

17. Gough DJ, Levy DE, Johnstone RW and Clarke CJ: IFNgamma signaling - does it mean JAK-STAT? Cytokine Growth Factor Rev 19: 383-394, 2008.

18. Jaruga B, Hong F, Kim WH and Gao B: IFN-gamma/STAT1 acts as a proinflammatory signal in $\mathrm{T}$ cell-mediated hepatitis via induction of multiple chemokines and adhesion molecules: a critical role of IRF-1. Am J Physiol Gastrointest Liver Physiol 287: G1044-G1052, 2004

19. Martinez FO, Gordon S, Locati $M$ and Mantovani A: Transcriptional profiling of the human monocyte-to-macrophage differentiation and polarization: new molecules and patterns of gene expression. J Immunol 177: 7303-7311, 2006.

20. Negishi H, Fujita Y, Yanai H, Sakaguchi S, Ouyang X, Shinohara M, Takayanagi $\mathrm{H}$, Ohba $\mathrm{Y}$, Taniguchi $\mathrm{T}$ and Honda K: Evidence for licensing of IFN-gamma-induced IFN regulatory factor 1 transcription factor by MyD88 in Toll-like receptor-dependent gene induction program. Proc Natl Acad Sci USA 103: 15136-15141, 2006.

21. Liu J, Guan X, Tamura T, Ozato K and Ma X: Synergistic activation of interleukin-12 p35 gene transcription by interferon regulatory factor-1 and interferon consensus sequence-binding protein. J Biol Chem 279: 55609-55617, 2004.

22. Ouyang X, Negishi H, Takeda R, Fujita Y, Taniguchi T and Honda K: Cooperation between MyD88 and TRIF pathways in TLR synergy via IRF5 activation. Biochem Biophys Res Commun 354: 1045-1051, 2007.

23. Toshchakov V, Jones BW, Perera PY, Thomas K, Cody MJ, Zhang S, Williams BR, Major J, Hamilton TA, Fenton MJ and Vogel SN: TLR4, but not TLR2, mediates IFN-beta-induced STAT1alpha/beta-dependent gene expression in macrophages. Nat Immunol 3: 392-398, 2002.

24. Fleetwood AJ, Dinh H, Cook AD, Hertzog PJ and Hamilton JA: GM-CSF- and M-CSF-dependent macrophage phenotypes display differential dependence on type I interferon signaling. J Leukoc Biol 86: 411-421, 2009.

25. Reis LF, Harada H, Wolchok JD, Taniguchi T and Vilcek J: Critical role of a common transcription factor, IRF-1, in the regulation of IFN-beta and IFN-inducible genes. EMBO J 11: 185-193, 1992.

26. Guo Z, Garg S, Hill KM, Jayashankar L, Mooney MR, Hoelscher M, Katz JM, Boss JM and Sambhara S: A distal regulatory region is required for constitutive and IFN-beta-induced expression of murine TLR9 gene. J Immunol 175: 7407-7418, 2005.

27. Liu J, Cao S, Herman LM and Ma X: Differential regulation of interleukin (IL)-12 p35 and p40 gene expression and interferon (IFN)-gamma-primed IL-12 production by IFN regulatory factor 1. J Exp Med 198: 1265-1276, 2003.

28. Krausgruber T, Blazek K, Smallie T, Alzabin S, Lockstone H, Sahgal N, Hussell T, Feldmann M and Udalova IA: IRF5 promotes inflammatory macrophage polarization and TH1-TH17 responses. Nat Immunol 12: 231-238, 2011.

29. Dalmas E, Toubal A, Alzaid F, Blazek K, Eames HL, Lebozec K, Pini M, Hainault I, Montastier E, Denis RG, et al: Irf5 deficiency in macrophages promotes beneficial adipose tissue expansion and insulin sensitivity during obesity. Nat Med 21: 610-618, 2015. 
30. Feng D, Sangster-Guity N, Stone R, Korczeniewska J, Mancl ME, Fitzgerald-Bocarsly P and Barnes BJ: Differential requirement of histone acetylase and deacetylase activities for IRF5-mediated proinflammatory cytokine expression. J Immunol 185: 6003-6012, 2010.

31. Mancl ME, Hu G, Sangster-Guity N, Olshalsky SL, Hoops K, Fitzgerald-Bocarsly P, Pitha PM, Pinder K and Barnes BJ: Two discrete promoters regulate the alternatively spliced human interferon regulatory factor-5 isoforms. Multiple isoforms with distinct cell type-specific expression, localization, regulation, and function. J Biol Chem 280: 21078-21090, 2005.

32. Tan RS, Taniguchi T and Harada H: Identification of the lysyl oxidase gene as target of the antioncogenic transcription factor, IRF-1, and its possible role in tumor suppression. Cancer Res 56: 2417-2421, 1996

33. Zimmermann A, Trilling M, Wagner M, Wilborn M, Bubic I, Jonjic S, Koszinowski U and Hengel H: A cytomegaloviral protein reveals a dual role for STAT2 in IFN-(gamma) signaling and antiviral responses. J Exp Med 201: 1543-1553, 2005.

34. Steen HC and Gamero AM: The role of signal transducer and activator of transcription-2 in the interferon response. J Interferon Cytokine Res 32: 103-110, 2012.

35. Taniguchi K, Hikiji H, Okinaga T, Hashidate-Yoshida T, Shindou H, Ariyoshi W, Shimizu T, Tominaga K and Nishihara T: Essential role of lysophosphatidylcholine acyltransferase 3 in the induction of macrophage polarization in PMA-treated U937 cells. J Cell Biochem 116: 2840-2848, 2015.

36. Maeß MB, Wittig B, Cignarella A and Lorkowski S: Reduced PMA enhances the responsiveness of transfected THP-1 macrophages to polarizing stimuli. J Immunol Methods 402: 76-81, 2014.

37. El Fiky A, Perreault R, McGinnis GJ and Rabin RL: Attenuated expression of interferon- $\beta$ and interferon- $\lambda 1$ by human alternatively activated macrophages. Hum Immunol 74: 1524-1530, 2013.
38. Stout RD, Watkins SK and Suttles J: Functional plasticity of macrophages: in situ reprogramming of tumor-associated macrophages. J Leukoc Biol 86: 1105-1109, 2009.

39. Siveen KS and Kuttan G: Role of macrophages in tumour progression. Immunol Lett 123: 97-102, 2009.

40. Jensen MA and Niewold TB: Interferon regulatory factors: critical mediators of human lupus. Transl Res 165: 283-295, 2015.

41. Paun A and Pitha PM: The IRF family, revisited. Biochimie 89: 744-753, 2007.

42. Salloum R and Niewold TB: Interferon regulatory factors in human lupus pathogenesis. Transl Res 157: 326-331, 2011.

43. Günthner R and Anders HJ: Interferon-regulatory factors determine macrophage phenotype polarization. Mediators Inflamm 2013: 731023, 2013.

44. Jaguin M, Houlbert N, Fardel O and Lecureur V: Polarization profiles of human M-CSF-generated macrophages and comparison of M1-markers in classically activated macrophages from GM-CSF and M-CSF origin. Cell Immunol 281: 51-61, 2013

45. Duechler M,Peczek L,Zuk K, Zalesna I, Jeziorski A and Czyz M: The heterogeneous immune microenvironment in breast cancer is affected by hypoxia-related genes. Immunobiology 219: $158-165,2014$.

46. Nicolini A, Carpi A and Rossi G: Cytokines in breast cancer. Cytokine Growth Factor Rev 17: 325-337, 2006.

47. Wang YC, He F, Feng F, Liu XW, Dong GY, Qin HY, Hu XB, Zheng MH, Liang L, Feng L, et al: Notch signaling determines the M1 versus M2 polarization of macrophages in antitumor immune responses. Cancer Res 70: 4840-4849, 2010.

48. Buijs JT, Stayrook KR and Guise TA: TGF- $\beta$ in the bone microenvironment: role in breast cancer metastases. Cancer Microenviron 4: 261-281, 2011.

49. Drabsch Y and ten Dijke P: TGF- $\beta$ signaling in breast cancer cell invasion and bone metastasis. J Mammary Gland Biol Neoplasia 16: 97-108, 2011. 